\section{Late Summer Irrigation of Water-stressed Peach Trees Reduces Fruit Doubles and Deep Sutures}

\author{
Dale F. Handley and R. Scott Johnson ${ }^{1}$ \\ Department of Pomology, University of California Kearney Agricultural \\ Center, Parlier, CA 93648
}

\section{Additional index words. Prunus persica, fruit buds, fruit disorders, water conservation}

In arid climates, fruit doubling has long been recognized as a problem in peaches (Prunus persica L. Batsch) and has been associated with water stress due to drought (Garcia, 1980; Patten, 1989) or deficit irrigation (Johnson et al., 1992; Larson et al., 1988). Another malady of peach fruit, termed deep suture, also seems to be related to water stress. The symptom of this disorder is a deep cleavage in the suture at the stem end of the fruit that extends at least half way toward the blossom end and renders the fruit unmarketable. Whereas most double fruit can be removed by normal hand thinning, deep sutures are difficult to detect on small fruitlets.

Substantial water savings can be achieved without sacrificing yield by withholding irrigation of early maturing peach cultivars after harvest (Johnson et al., 1992). The main disadvantage is the increased number of double fruit and deep sutures. This study was initiated to determine if reirrigation during carpel differentiation in the flower buds (late August) could substantially reduce these disorders while still saving water.

A 0.5-ha block of central leader-trained 'Spring Lady' peach trees on 'Nemaguard' rootstock planted in 1984 at a $3.9 \times 2.0-\mathrm{m}$ spacing at the Kearney Agricultural Center, Parlier, Calif., was used for this study. The orchard soil was a Hanford sandy loam (typic xerothents) with $\approx 400 \mathrm{~mm}$ of available water in a 3-m soil profile. A randomized completeblock design was used with two treatments and six replications. A plot consisted of eight trees in a row with two border trees on either end and aborder row on either side. The control treatment was irrigated every 1 to $2 \mathrm{~d}$ from April through October with one $38 \mathrm{~L} \cdot \mathrm{h}^{-1}$ microsprinkler per tree. Amounts were based on estimated evapotranspiration $\left(\mathrm{ET}_{\mathrm{c}}\right)$, calculated from reference crop water use $\left(\mathrm{ET}_{\mathrm{o}}\right)$ and crop coefficients $\left(\mathrm{K}_{\mathrm{c}}\right)$ for deciduous fruit trees (Goldhamer, 1989). The stressed treatment, initiated after harvest in May 1988, was irrigated at the same frequency but received only $25 \%$ of the control volume. In 1989 and 1990, the same treatments were imposed after harvest except that half of

Received for publication 28 June 1999. Accepted for publication 23 Nov. 1999. The cost of publishing this paper was defrayed in part by the payment of page charges. Under postal regulations, this paper therefore must be hereby marked advertisement solely to indicate this fact.

1'E-mail address: sjohnson@uckac.edu the deficit irrigation plots were heavily irrigated during the period of carpel differentiation (late August). In 1989, this "rewatered" treatment received $171 \% \mathrm{ET}_{\mathrm{c}}$ from $18 \mathrm{Aug}$. to $27 \mathrm{Sept}$. In 1990, it received $132 \% \mathrm{ET}_{\mathrm{c}}$ from 1 Aug. to 10 Sept.

Percentage of double fruit at thinning time was measured on 12 shoots per plot 1 month after bloom. Final numbers of doubles and deep sutures were determined by evaluating every fruit harvested in late May. Statistical analysis was run separately each year and consisted of standard analysis of variance and Duncan's multiple range test (CoHort Software, Minneapolis, Minn.).

Substantial water savings were achieved by reducing irrigation after harvest (Table 1); however, formation of double fruit was extensive $(33 \%$ to $51 \%)$ and similar to levels reported from other studies (Garcia 1980; Johnson et al., 1992; Larson et al., 1988). Even after hand thinning, the stress treatment still had $3 \%$ to $4 \%$ doubles at harvest, vs. $<1 \%$ for the control. In addition, deep sutures ranged from $10 \%$ to $15 \%$ of the harvested fruit in the stress treatment vs. $1 \%$ to $4 \%$ for the control.

Close examination of developing fruit suggests deep sutures start as doubles, but early on one of the two fruit aborts and may not be evident at harvest (Fig. 1, top). However, its presence during early development interferes with proper suture closing of the other fruit. Thus, doubles and deep sutures are both the result of formation of two carpels, caused by water stress.

Table 1. The effect of postharvest water stress and latesummer rewatering on fruit doubles and deep sutures in 'Spring Lady' peach fruit.

\begin{tabular}{lcccc}
\hline & & \multicolumn{3}{c}{ Treatment } \\
\cline { 3 - 5 } Parameter & Year & Control & Stress & Rewater \\
\hline Total applied & & & & \\
water (mm) & 1988 & $1230 \mathrm{a}^{\mathrm{z}}$ & $390 \mathrm{~b}$ & --- \\
& 1989 & $1140 \mathrm{a}$ & $455 \mathrm{c}$ & $720 \mathrm{~b}$ \\
& 1990 & $1189 \mathrm{a}$ & $518 \mathrm{c}$ & $884 \mathrm{~b}$ \\
Doubles at & & & & \\
thinning (\%) & 1989 & $0.4 \mathrm{~b}$ & $33.4 \mathrm{a}$ & --- \\
& 1990 & $1.7 \mathrm{c}$ & $51.5 \mathrm{a}$ & $20.6 \mathrm{~b}$ \\
& 1991 & $7.5 \mathrm{~b}$ & $44.8 \mathrm{a}$ & $2.9 \mathrm{~b}$ \\
Doubles at & & & & \\
harvest (\%) & 1989 & $0.1 \mathrm{~b}$ & $2.5 \mathrm{a}$ & --- \\
& 1990 & $0.4 \mathrm{~b}$ & $4.2 \mathrm{a}$ & $1.5 \mathrm{~b}$ \\
& 1991 & $0.3 \mathrm{~b}$ & $4.2 \mathrm{a}$ & $0.3 \mathrm{~b}$ \\
Deep sutures & & & & \\
at harvest (\%) & 1989 & $1.2 \mathrm{~b}$ & $12.0 \mathrm{a}$ & --- \\
& 1990 & $3.7 \mathrm{~b}$ & $14.8 \mathrm{a}$ & $3.7 \mathrm{~b}$ \\
& 1991 & $4.4 \mathrm{~b}$ & $10.1 \mathrm{a}$ & $4.1 \mathrm{~b}$ \\
\hline${ }^{2}$ Mean separation within rows by Duncan's multiple range
\end{tabular}
test $(P \leq 0.05)$.
Microscopic observation of 60 flower buds per week in 1988 showed no carpel differentiation on 24 Aug., 22\% on 31 Aug., and 90\% on 8 Sept., which is similar to other reports from California (Garcia, 1980). Double carpels were also observed at the same time (Fig. 1, bottom). Therefore, in 1989 the rewatered treatment was initiated on $18 \mathrm{Aug}$. in order to relieve stress by the first week of September. This significantly reduced doubling to $\approx 21 \%$, but this level was still higher than desired. Accordingly, in 1990 rewatering was initiated on 1 Aug., which reduced doubles to the same level as that found in the fully irrigated control. Doubles and deep sutures at harvest were reduced to control levels in both years. Substantial water savings over the control were still achieved. These data support the conclusion that doubles and deep sutures in fruit from water-stressed peach trees can be reduced to control levels by relieving the stress shortly before and during carpel differentiation.

\section{Literature Cited}

Garcia, M.A. 1980. Influence of different irrigation regimes on flower bud formation and development in peach trees. MS. Thesis, Univ. of California, Davis.

Goldhamer, D.A. 1989. Irrigation scheduling: A guide for efficient on-farm water management. Univ. of Calif., Agr. and Natural Resources. Leaflet 21453.

Johnson. R.S., D.F. Handley, and T.M. DeJong. 1992. Long-term response of early maturing peach trees to postharvest water deficits. J. Amer. Soc. Hort. Sci. 117:881-886.

Larson, K.D., T.M. DeJong, and R.S. Johnson. 1988. Physiological and growth responses of mature peach trees to postharvest water stress. J. Amer. Soc. Hort. Sci. 113:296-300.

Patten, K., G. Nimr, and E. Neuendorff. 1989. Fruit doubling of peaches as affected by water stress. Acta Hort. 254:319-321.
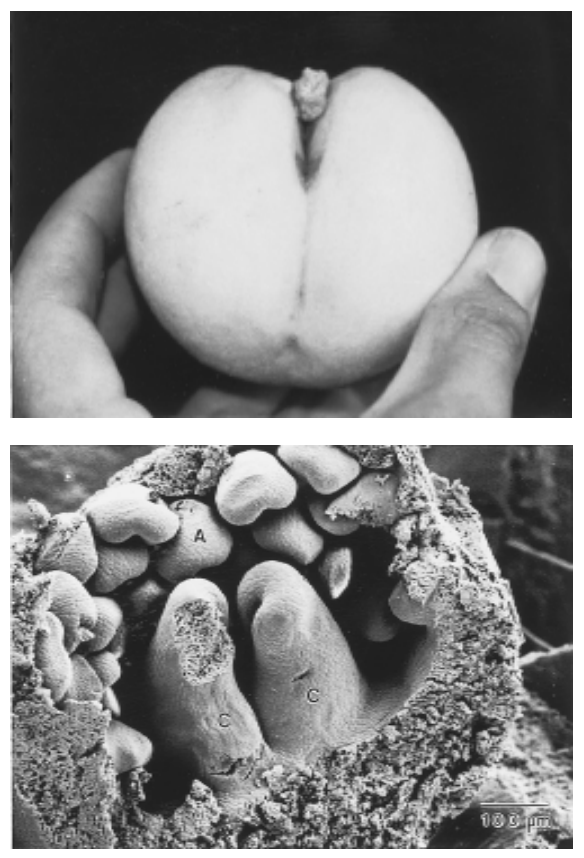

Fig. 1. (top) Deep sutured peach fruit with remnant of aborted second fruit (originally a double) that remained within the suture until harvest. (bottom) Scanning electron micrograph showing anthers (A) and double carpels (C) developing within a flower bud in the fall following the stress treatment. 